Marc A. Pilato MD, Bruno Bissonnette MD, Jerrold Lerman MD

\title{
Transcranial Doppler: response of cerebral blood-flow velocity to carbon dioxide in anaesthetized children
}

To determine the effect of carbon dioxide on the cerebral circulation in anaesthetized infants and children, 13 healthy children, ASA physical status I or II, between three months and seven years of age and scheduled for urologic surgery, were studied. Anaesthesia was induced with thiopentone and vecuronium. After tracheal intubation, anaesthesia was maintained with 70 per cent nitrous oxide in oxygen, fentanyl $2 \mu \mathrm{g} \cdot \mathrm{kg}^{-1}$. vecuronium $0.05 \mathrm{mg} \cdot \mathrm{kg}^{-1}$ and $0.8-1.0$ per cent end-tidal isoflurane. A caudal block was performed before surgery. Systolic arterial pressure, heart rate, oxygen saturation, temperature, and end-tidal isoflurane were maintained constant. Ventilation was adjusted to achieve an end-tidal $\mathrm{PCO}_{2}\left(\mathrm{PETCO}_{2}\right)$ of 20 $\mathrm{mmHg}$. The $\mathrm{PETCO}_{2}$ was then randomly adjusted between 20 and $80 \mathrm{mmHg}$ by the addition of carbon dioxide from an exogenous source. Cerebral blood flow velocity increased logarithmically and directly with the PETCO $\mathrm{P}_{2}\left(r^{2}=0.56\right)$. There were no complications associated with the use of transcranial Doppler sonography. These data indicate that $\mathrm{CO}_{2}$ has a direct effect on the velocity of blood in the middle cerebral artery in infants and children anaesthetized with isoflurane.

La présente étude a pour but de déterminer l'effet du dioxyde de carbone $\left(\mathrm{CO}_{2}\right)$ sur la circulation cérébrale de treize enfants,

\section{Key words}

ANAESTHESIA: paediatric;

BRAIN: blood flow, carbon dioxide tension;

MEASUREMENT TECHNIQUES: transcranial Doppler

ultrasound;

VENTILATION: carbon dioxide tension.

From the Department of Anaesthesia and the Research Institute, The Hospital for Sick Children, University of Toronto, Toronto, Ontario, Canada M5G 1X8. Presented, in part, at the Annual Meeting of the American Society of Ancsthesiology, October 1989.

Address correspondence to: Dr. Bruno Bissonnette, Department of Anaesthesia, The Hospital for Sick Children, 555 University Avenue, Toronto, Ontario, Canada, M5G 1 X8.

Accepted for publication 15th August, 1990
ASA I ou II agés entre trois mois et sept ans, subissant une intervention chirurgicale urologique. L'induction anesthésique a été pratiquée à l'aide de thiopentone et de vécuronium. Après I'intubation trachéale, le maintien de l'anesthésie a été assurée par la respiration d'un mélange de 70 pour cent de protoxyde d'azote dans de l'oxygéne, fentanyl $2,0 \mu \mathrm{g} \cdot \mathrm{kg}^{-1}$, vécuronium $0.05 \mathrm{mg} \cdot \mathrm{kg}^{-1}$ et l'emploi d' isoflurane $0,8-1,0$ pour cent. Un bloc caudal était administré avant le début de la chirurgie. La pression artérielle systolique, le rythme cardiaque, la saturation en oxygène, la temperature et la concentration d' isoflurane en fin d'expiration étaient maintenus constants. La ventilation mécanique était ajustée afin de produire une tension de $\mathrm{CO}_{2}$ de $20 \mathrm{mmHg}$ en fin d'expiration $\left(\mathrm{PETCO}_{2}\right)$. Utilisant une source exogène de $\mathrm{CO}_{2}$, la PETCO était aléatoirement ajustée entre 20 et $80 \mathrm{mmHg}$. La vélocité du débit sanguin cérébrale s'est accrue d' une façon logarithmique et paralléle à l'augmentation de la PETCO $\mathrm{O}_{2}\left(r^{2}=0,56\right)$. Aucune complication n'est survenue. de l'utilisation d'un sonographe Doppler transcranien. Ces résultats démontrent que le $\mathrm{CO}_{2}$ possède un effet direct sur la vélocité du sang dans l'artère moyenne cérébrale chez les enfants anesthésiés avec de l'isoflurane.

Transcranial doppler sonography (TCD), as described first by Aaslid in 1982, is a non-invasive technique that measures cerebral blood flow velocity using the Doppler principle. ${ }^{1}$ This principle is based on the fact that ultrasonic waves penetrate and scatter in two tissues of different densities. When these waves encounter an interface, that is tissues of different densities, the waves are reflected back to the source at frequencies that differ from the emitted frequency. The difference between the emitted and reflected ultrasonic frequencies is used to calculate the velocity of the moving tissue - in this instance, blood.

Although Doppler techniques have been applied to peripheral limb arteries for many years, investigators have only recently measured the blood velocity in intracranial arteries. ${ }^{1}$ Since the bones of the skull both absorb and reflect ultrasound in the $4-9 \mathrm{MHz}$ frequency 
range, ultrasonography of the intracerebral vessels has been limited to infants with open fontanelles. In order to facilitate ultrasound studies in older children with closed fontanelles, the Doppler technique has been modified. Investigators restricted the site of application of the ultrasound probe to those areas of the skull where the bone is relatively thin, i.e., the temporal window. To augment further the transmission of ultrasound waves through the skull, the frequency of the Doppler signal was decreased from the 4-9 $\mathrm{MHz}$ to 1-2 $\mathrm{MHz}$.

An additional modification was the use of pulsed wave rather than continuous wave ultrasound signals. The former senses lower frequency signals reflected from red cells and enables reconstruction of a pulse signal whereas the latter senses higher frequency signals reflected from the walls of blood vessels. All of these modifications greatly improved the quality of Doppler measurements of the velocity of blood in the large basal intracranial arteries particularly those in the Circle of Willis in older children with closed fontanelles. ${ }^{2}$

Carbon dioxide $\left(\mathrm{CO}_{2}\right)$ affects the cerebral circulation by dilating the cerebral arteries and increasing cerebral blood flow (CBF). ${ }^{3}$ In adults, this arterial dilatation occurs only at the level of the small resistance vessels or arterioles. ${ }^{4}$ Carbon dioxide has no direct effect on the diameter of the large basal artcries. ${ }^{4}$ Changes in the diameter of the small resistance vessels directly affect both the cerebral blood flow velocity and the cerebral blood flow. ${ }^{5,6}$ Carbon dioxide rapidly equilibrates across biological membranes and alters the perivascular $\mathrm{pH}$. Since the perivascular $\mathrm{pH}$ is an important determinant of cerebrovascular reactivity, $\mathrm{CO}_{2}$ exerts a rapid and considerable effect on $\mathrm{CBF}^{3}$ Although $\mathrm{CO}_{2}$ is believed to act in a similar manner in children, studies in anacsthetized children are not available.

In order to investigate this effect, we designed the following study: (1) to evaluate the applicability of TCD monitoring perioperatively in an aesthetized infants and children, and (2) to determine the effect of $\mathrm{CO}_{2}$ on cerebral blood flow velocity in anaesthetized healthy infants and children.

\section{Methods}

\section{Practical procedure}

Following approval from the human subjects review committee, written informed consent was obtained from the parents of 13 healthy ASA physical status I or Il infants and children, three months to seven years of age, who were scheduled for elective urological surgery. All children were fasting and unpremedicated. Patients with cardiac or neurologic disease were excluded. All patients were supine and horizontal throughout the study.
Anaesthesia was induced with thiopentone $5 \mathrm{mg} \cdot \mathrm{kg}^{-1}$ and vecuronium $0.1 \mathrm{mg} \cdot \mathrm{kg}^{-1}$ intravenously. After tracheal intubation, the lungs were ventilated with intermittent positive-pressure ventilation with peak inspiratory pressures of $20-25 \mathrm{~cm} \mathrm{H}_{2} \mathrm{O}$. Ventilation was adjusted to maintain a $\mathrm{PETCO}$ of $40 \mathrm{mmHg}$. Positive end-expiratory pressure was avoided. Fresh gas flow remained unchanged throughout the study. Anaesthesia was maintained with 70 per cent $\mathrm{N}_{2} \mathrm{O} / \mathrm{O}_{2}$, fentanyl $2 \mu \mathrm{g} \cdot \mathrm{kg}^{-1}$, vecuronium $0.05 \mathrm{mg} \cdot \mathrm{kg}^{-1}$ and $0.8-1.0$ per cent end-tidal jsoflurane. The end-tidal concentration of isoflurane was age-adjusted to $1 \mathrm{MAC}{ }^{7} \mathrm{~A}$ caudal block $\left(1 \mathrm{ml} \cdot \mathrm{kg}^{-1}\right.$, 0.25 per cent bupivacaine without epinephrine) was administered to all patients before surgical incision. Normothermia was maintained. All patients received lactated Ringer's solution $\left(2 \mathrm{ml} \cdot \mathrm{kg}^{-1} \cdot \mathrm{hr}^{-1}\right)$ as maintenance fluid, and $3 \mathrm{ml}$ lactated Ringer's solution for each $\mathrm{ml}$ of blood loss. Systolic arterial pressure, heart rate, oxygen saturation, end-tidal isoflurane concentration, and the inspired $\mathrm{N}_{2} \mathrm{O}$ and $\mathrm{O}_{2}$ fractions were unchanged throughout the study period. The end-tidal concentrations of isoflurane and $\mathrm{CO}_{2}$ were measured from the distal end of the tracheal tube ${ }^{8}$ and analyzed with a calibrated Puritan-Bennett Datex 254 airway gas monitor (Datex Instrumentation Corp., Helsinki, Finland). The gas monitor was calibrated before each use using a reference gas mixture.

After baseline measurements were recorded at a PETCO ${ }_{2}$ of $40 \mathrm{mmHg}$, the lungs were hyperventilated to a $\mathrm{PETCO}_{2}$ of $20 \mathrm{mmHg}$. The mean intrathoracic pressure was maintained constant throughout the study. All measurements were recorded at $\mathrm{PETCO}_{2}$ values between 20 and $80 \mathrm{mmHg}$ using an exogenous source of carbon dioxide. Random values of $\mathrm{PETCO}_{2}$ were assigned prior to the case. After administration of $\mathrm{CO}_{2}$ for five minutes, three consecutive measurements of mean cerebral blood flow velocity (CBFV) and pulsatility index (PI), a resistance index, in the middle cerebral artery (MCA) were recorded at one-minute intervals. The PI was calculated for each MCA velocity measurement according to the formula: (end-systolic flow velocity - enddiastolic flow velocity)/end-systolic flow velocity, as adapted from Pourcelot's index of resistance. ${ }^{9}$ At each steady-state condition, systolic arterial pressure, heart rate, oxygen saturation, temperature, end-tidal isoflurane concentration and inspired $\mathrm{N}_{2} \mathrm{O}$ and $\mathrm{O}_{2}$ fractions were recorded.

\section{Doppler instrumentation}

The TCD monitor (TC2-64B, EME, Carolina Medical Electronics Inc., King NC) was used to determine the CBFV. This monitor has the following characteristics: pulsed wave ultrasonic frequency, $2 \mathrm{MHz}$; emitting area, 


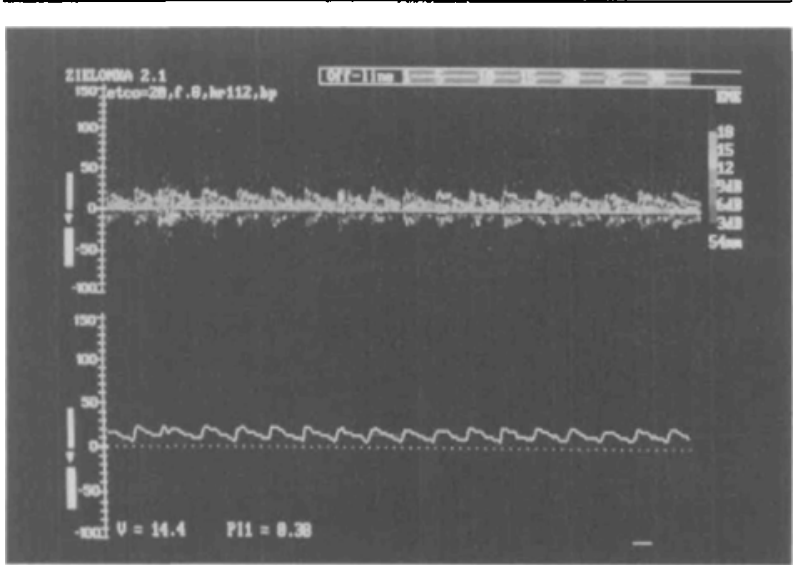

FIGURE 1 Spectral display of the Doppler signal from the middle cerebral arery at $\mathrm{PETCO}_{2}$ of $20 \mathrm{mmHg}$. The numeric display in the bottom left quadrant is the mean CBFV and one harmonic of the Fourier $\mathrm{Pl}$ value (PI) corresponding to the spectra on the lower graph. CBFY was $14.4 \mathrm{~cm} \cdot \mathrm{sec}^{-1}$ and PI was 0.38 .

$1.5 \mathrm{~cm}^{2}$; effective depth range, $3.0-10.0 \mathrm{~cm}$; emitted maximum ultrasonic power, $100 \mathrm{~mW}$. The frequency spectra of the Doppler signals were displayed on a real time spectrum analyzer which allowed a clear visual representation of flow for unambiguous interpretation of the CBFV waveform.

The pulsed wave range-gated TCD probe was placed over the temporal window of the skull just cephalad to the zygomatic arch, approximately $2 \mathrm{~cm}$ in front of the tragus. Once positioned over the temporal window, the TCD probe was secured using a telescopic device to facilitate continuous measurements of CBFV in the MCA. The Doppler signal was optimized for clear and accurate determinations by adjusting the depth of the signal, scale and gain of the measurement and the angle of insonation.

The CBFV, PI, and the graphic display of systolic and diastolic cerebral velocities in the MCA were obtained during haemodynamic steady-state periods at each PET$\mathrm{CO}_{2}$ value. The Doppler frequency spectrum was displayed on a frequency analyzer and then reconstructed following fast Fourier transformation. Doppler waveforms with low signal-to-noise ratios or those that included signals from adjacent vessels were excluded from analysis. The outline or envelope of the spectra was used to determine the CBFV within the MCA by positioning the cursor on the individual frequency outlines. The mean velocity was determined by the weighted average velocity. The relative contribution of the Fourier coefficients were compared and the velocity profile was reconstructed to provide more accurate estimates of the mean velocity and pulsatility measurements. The Fourier pulsatility index provided a precise analysis of the pulsatility of displayed waveforms.

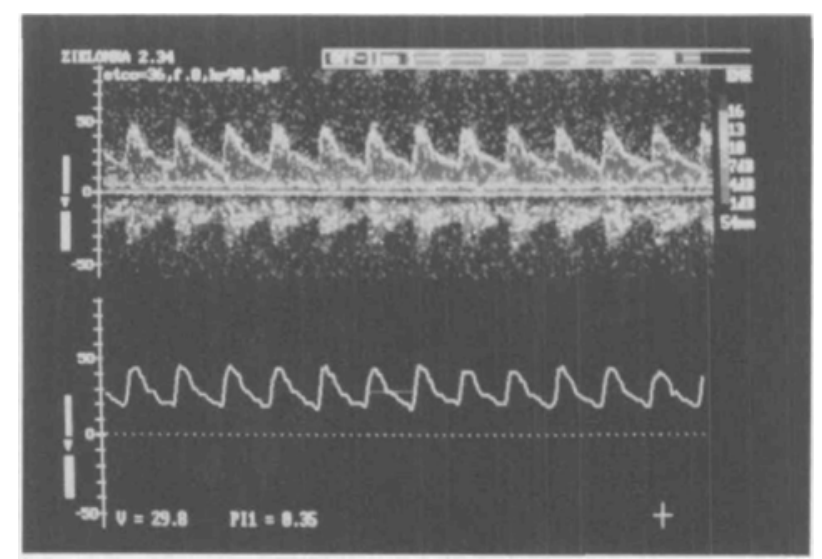

FIGURE 2 Spectral display of the Doppler signal from the middle cerebral artery at PETCO $\mathrm{P}_{2}$ of $36 \mathrm{mmHg}$. In this child, the mean CBFV was $29.8 \mathrm{~cm}^{\prime} \mathrm{sec}^{-1}$ and the PI was 0.35 . Note the increase in mean CBFV from 14.4 in Figure 1 to $29.8 \mathrm{~cm} \cdot \mathrm{sec}^{-1}$ in this figure.

\section{Statistical analysis}

The mean \pm standard deviation (SD) age and weight were determined. The relationships between $\mathrm{PETCO}_{2}$ and both CBFV and PI were determined using non-linear regression analysis. The dependence of both TCD variables on the $\mathrm{PeTCO}_{2}$ was determined using the coefficient of determination $\left(r^{2}\right)$. The slope of the semi-logarithmic transformation of the $\mathrm{PETCO}_{2}-\mathrm{CBFV}$ data was compared with horizontal using Student's $t$ test. Statistical significance $(P<0.05)$ was accepted.

\section{Results}

The mean \pm SD age and weight of the 13 infants and children was $3.5 \pm 2.0 \mathrm{yr}$ and $18.6 \pm 8.9 \mathrm{~kg}$ respectively. Systolic arterial blood pressure, heart rate, arterial oxygen saturation and end-tidal isoflurane concentration did not change significantly during the study. The haemoglobin concentration for the 13 patients was between 120 and $143 \mathrm{~g} \cdot \mathrm{L}^{-1}$. Doppler recordings of MCA blood velocity were completed in all infants and children at $\mathrm{PETCO}_{2}$ values between 20 and $80 \mathrm{mmHg}$. Figures $1-3$ illustrate the spectral display of the doppler signal from the MCA of one child anaesthetized at PETCO 2 values of 20,36 and 74 $\mathrm{mmHg}$ respectively. The CBFV increased logarithmically as the $\mathrm{PeTCO}_{2}$ increased $\left(r^{2}=0.56\right.$ ) (Figure 4). The slope of the semi-logarithmic transformation of the data was significantly different from horizontal (i.e., slope $=$ $0)(P=0.001)$. The PI decreased logarithmically as the $\mathrm{PETCO}_{2}$ increased $\left(\mathrm{r}^{2}=0.41\right)$ (Figure 5). There were no complications from the use of the TCD in this study.

\section{Discussion}

Physiological factors extrinsic to the brain can alter its local chemical environment. Carbon dioxide rapidly 


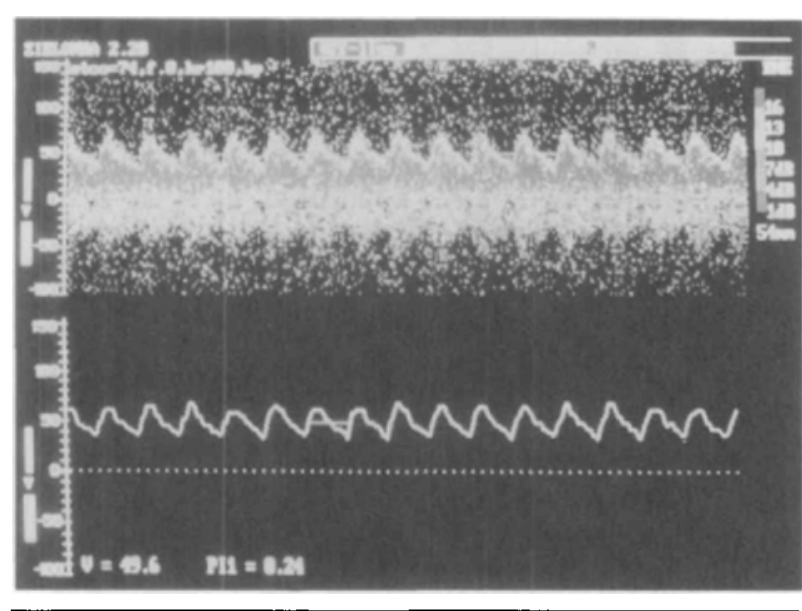

FIGURE 3 Spectral display of the Doppler signal from the MCA at $\mathrm{PETCO}_{2}$ of $74 \mathrm{mmHg}$. Note the increase in mean CBFV from 29.8 to $49.6 \mathrm{~cm} \cdot \mathrm{sec}^{-1}$ with a reciprocal decrease in PI from 0.35 to 0.24 as $\mathrm{PETCO}_{2}$ increased from $36 \mathrm{mmHg}$ (Figure 2) to $74 \mathrm{mmHg}$ in this figure.

equilibrates across biological membranes, thereby altering the local chemical environment. Our results demonstrate that CBFV changes logarithmically and directly with $\mathrm{PETCO}_{2}$ in anaesthetized infants and children. The relationship between $\mathrm{PETCO}_{2}$ and the per cent change in CBFV is a sigmoid curve that is linear for $\mathrm{PETCO}_{2}$ values between 25 and $75 \mathrm{mmHg}$. In this study, CBFV increased approximately $1.6 \mathrm{~cm} \cdot \mathrm{sec}^{-1} \cdot \mathrm{mmHg}^{-1} \mathrm{CO}_{2}$ with a coefficient of determination $\left(\mathrm{r}^{2}\right)$ of 0.56 . This is consistent with previously published values for adults, $1.4 \mathrm{~cm} \cdot \mathrm{sec}^{-1}$. $\mathrm{mmHg}^{-1}$. The intermediate $\mathrm{r}^{2}$ value probably reflects the large interindividual variability in the CBFV in the range of $\mathrm{PCO}_{2} 30-50 \mathrm{mmHg}$.

The cerebral vascular resistance is difficult to measure non-invasively. However, several expressions based on the Fourier transformed transcranial Doppler frequency spectra have been developed to estimate vascular resistance. One such expression is the ratio of the difference between corresponding systolic and diastolic velocities, and the systolic velocity. ${ }^{9}$ This expression, also known as the pulsatility index or Pourcelot index (PI) has been shown to correlate closely with the cerebrovascular resistance. We found that $P I$ increased logarithmically as the $\mathrm{PeTCO}_{2}$ decreased from 80 to $20 \mathrm{mmHg}$. This relationship is consistent with our understanding of the effects of $\mathrm{CO}_{2}$ on the resistance of cerebral vasculature. However, we were surprised that the $r^{2}$ for PI was only 0.41 . We attributed the low $r^{2}$ value to the large interindividual variability in the effect of $\mathrm{PETCO}_{2}$ on cerebrovascular reactivity.

Several studies have compared the relationship between the CBFV as measured with the TCD and CBF.

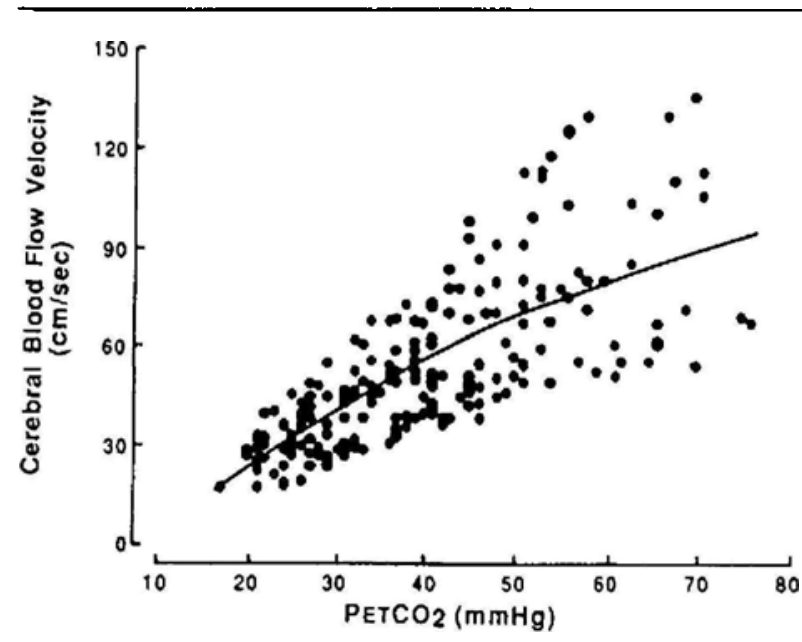

FIGURE 4 Logarithmic relationship between the $\mathrm{PETCO}_{2}$ and the CBFV of the MCA $\left(r^{\prime}=0.56\right)$.

They found the CBFV measurements obtained with pulsed wave range-gated transcranial sonography in both neonates and adults correlated with standard methods used to measure CBF, with correlation coefficients between 0.70 and $0.93 .^{10-12}$ Furthermore, the correlation between TCD and $\mathrm{Xe}^{133}$ measurements of $\mathrm{CBFV}$ and $\mathrm{PI}$ were consistently greater for the range gated than for continuous wave Doppler technique. ${ }^{11}$ These close correlations in patients of varied ages suggest that changes in the CBFV as measured by TCD sonography over a large range accurately reflect changes in CBF.

Since the TCD is non-invasive, and applied only using landmarks on the skull, there are several assumptions when evaluating the effectiveness of this methodology. The Doppler shift is expressed by the following formula:

$\mathrm{F}=2 \cdot \mathrm{FO} \cdot \mathrm{v} \cdot \cos \mathrm{a} / \mathrm{c}$

Where $F=$ the doppler shift $(\mathrm{Hz}), \mathrm{FO}=$ the mean frequency of the emitted ultrasound, $v=$ the blood flow velocity $\left(\mathrm{cm} \cdot \mathrm{sec}^{-1}\right), \mathrm{a}=$ the angle between the direction of the transmitted sound beam and the axis of the blood flow, and $c=$ the velocity of sound in tissue $(1,550$ $\mathrm{m} / \mathrm{sec}$ ). The Doppler shift is proportional to the blood flow velocity when the emitting frequency $\mathrm{FO}$ and the angle a remain constant.

It is difficult to determine the angle between the ultrasonic beam and the intracranial arteries, i.e., the insonating angle. If the angle is sharp, then accurate measurements of velocity are possible. If the angle is between $0^{\circ}$ and $30^{\circ}$, then its cosine will vary between 1 and 0.86 . Thus the maximum error is less than 15 per cent. Under such conditions, one can assume the true velocity $\mathrm{v}\left(\mathrm{cm}^{\cdot} \mathrm{sec}^{-1}\right)$ is given by the relation: $\mathrm{v}=$ $0.039 \cdot f$ where $f$ is the doppler frequency shift. $3,7,13$ 


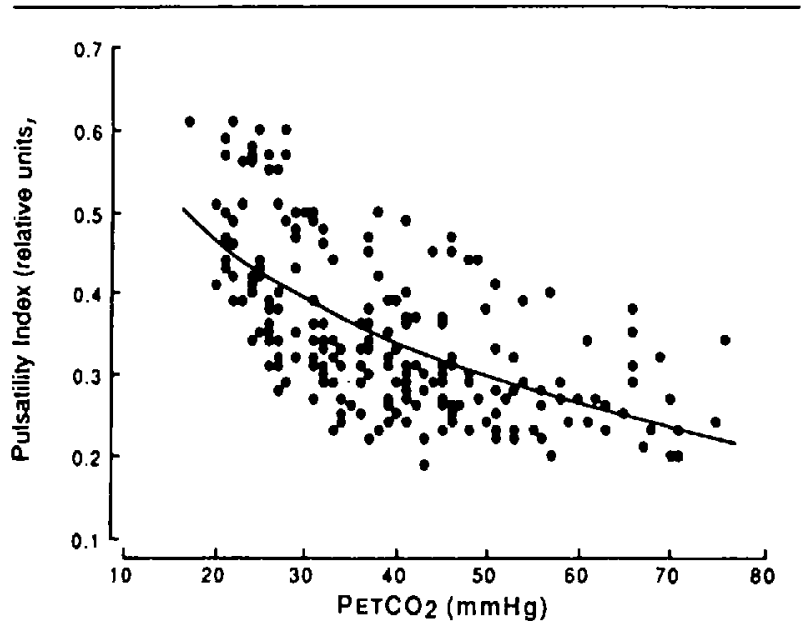

FIGURE 5 Logarithmic relationship between the $\mathrm{PETCO}_{2}$ and the Fourier PI of the MCA $\left(r^{\prime}=0.41\right)$.

We assumed that the angle of insonation remained constant during the study. The angle of the MCA at its site of origin from the internal carotid artery is almost perpendicular to the temporal window used in this study. Therefore, the column of blood in the MCA would move directly towards the ultrasound probe. If the Doppler probe is positioned axial to the blood flow, then the magnitude of this error is minimized. In order to minimize the intraindividual variability of CBFV measurements, the probe was fixed in position for the duration of the study once the probe position had been optimized.

Another assumption underlying the relationship between CBFV and CBF is that the diameter of the middle cerebral artery remains constant throughout the study period. ${ }^{3}$ Angiographic studies of the basal cerebral arteries in adults have shown that the diameter of these arteries remains constant despite large changes in the $\mathrm{PCO}_{2}$ or other extrinsic physiological factors as demonstrated by direct observation of pial vessels. ${ }^{4.14}$ If the diameter of the MCA were to increase marginally as $\mathrm{PETCO}_{2}$ increased, then the measured increase in CBFV would underestimate the true effect of $\mathrm{CO}_{2}$ on $\mathrm{CBF}$.

We were surprised to observe a large dispersion in CBFVs at high PETCO ${ }_{2}$ values. Markwalder et al. noted a similar finding in awake adults breathing seven per cent $\mathrm{CO}_{2} .{ }^{5}$ They attributed this large dispersion to restlessness and dyspnoea in their patients. However, our patients were anaesthetized and therefore demonstrated none of these behaviours. Several factors could explain the observed dispersion: (1) an increase in the error in CBFV measurement at high $\mathrm{PETCO}_{2}$ values, (2) interindividual variability in the CBFV response to high $\mathrm{CO}_{2}$ levels on the diameter of the MCA (as discussed above).

The time constant for the acute effects of $\mathrm{CO}_{2}$ on cerebral arterial circulation is approximately one minute. ${ }^{2}$ We administered $\mathrm{CO}_{2}$ for five minutes before commencing the study to ensure the cerebral arteriolar response to $\mathrm{CO}_{2}$ was complete. This exceeds the equilibration period used by others. $^{5}$ If the five-minute equilibration period had been inadequate, then CBFV would have changed between the first and third measurements of CBFV in any individual patient. However, the intraindividual coefficient of variation of these repeated measurements was only five per cent. This small coefficient supports our contention that the arteriolar response to $\mathrm{CO}_{2}$ is complete within five minutes in anaesthetized children.

The cerebrovascular response to carbon dioxide also depends on the arterial blood pressure. ${ }^{16-17}$ Although Markwalder et al. reported small increases in mean arterial blood pressure during profound hypercapnia in adults, they did not discuss the effects these changes may have on the CBFV measurements. ${ }^{5}$ A caudal block was administered to all children to attenuate the sympathetic response to surgical stimulation. To obviate any possible effects of changes in arterial pressure in this study, the systolic arterial blood pressure was maintained constant throughout.

Intrathoracic pressure is an important determinant of the right atrial pressure and therefore cerebral venous pressure. A constant mean intrathoracic pressure was maintained for each patient by initially adjusting the ventilator settings to produce a $\mathrm{PETCO}_{2}$ of $20 \mathrm{mmHg}$. The $\mathrm{PETCO}_{2}$ was then randomly adjusted to values between 20 and $80 \mathrm{mmHg}$ by the addition of exogenous carbon dioxide. Thus, a constant mean intrathoracic pressure was maintained throughout in the present study.

We used end-tidal $\mathrm{CO}_{2}$ measurements to estimate the arterial $\mathrm{PCO}_{2}$ based on previous studies in which we showed that both single-breath 16 and continuous distal ${ }^{7}$ PETCO $\mathrm{Cl}_{2}$ closely approximate the $\mathrm{PaCO}_{2}$ in healthy infants and children.

In summary, we have found the TCD to be a reliable device to measure CBFV in anaesthetized children. We have demonstrated that in healthy anaesthetized children, the $\mathrm{PETCO}_{2}$ directly affects the CBFV in the MCA. Since CBFV has been shown to correlate with the CBF, this device may be used to estimate changes in CBF within the physiologic range in anaesthetized children.

\section{Acknowledgments}

The authors thank the staff of the Carolina Medical Electronics company who provided the transcranial Doppler monitor. The authors are also grateful to Drs. Churchill, Mclorie, and Khoury from the Department of Urology for their cooperation and patience during this study. 


\section{References}

1 Aaslid $R$, Markwalder TM, Nornes $H$. Noninvasive transcranial Doppler ultrasound recording of flow velocity in basal cercbral arteries. J Neurosurg 1982; 57: 769-74.

2 Bode H. Cerebral Hemodynamics. In: Bode H (Ed.). Pediatric Applications of Transcranial Doppler Sonography. New York: Springer-Verlag Wcin, 1988; 4-8.

3 Shapiro $H M$. Anesthesia effects upon cerebral blood flow, cerebral metabolism, and the clectroencephalogram In: Miller RD (Ed.). Anesthesia. New York: Churchill Livingstone, Inc. 1986; 795-824.

4 Huber P. Handa J. Effect of contrast material, hypercapnia, hyperventilation, hypertonic glucose and papaverine on the diameter of the cerebral arteries angiographic determination in man. Invest Radiol 1967; 2: 17-32.

5 Markwalder TM, Grolimund P, Seer RW, Roth F, Aaslid

$R$. Dependency of blood flow velocity in the middle cerebral artery on end-tidal carbon dioxide partial pressure - a transcranial ultrasound Doppler study. J Cercb Blood Flow Metab 1984; 4: 368-72.

6 Aaslid $R$. Cerebral hemodynamics. In: Aaslid R (Ed.). Transcranial Doppler Sonography. New York: Springer-Verlag Wein, 1986;60-85.

7 Cameron $C B$, Robinson S, Gregory GA. The minimum anesthetic concentration of isoflurane in children. Anesth Analg 1984; 63: 418-20.

8 Badgwell JM, McLeod ME, Lerman J, Creighton $R E$. End-tidal $\mathrm{PCO}_{2}$ measurements sampled at the distal and proximal ends of the endotracheal tube in infants and children. Anesth Analg 1987; 66: 959-64.

9 Pourcelot $L$. Diagnostic ultrasound for cercbral vascular disease. In: Donald I, Levi S (Eds.). Present and Future of Diagnostic Ultrasound. Rotterdam: Kooker Scientific Publication, 1976; 141-7.

10 Bishop CCR, Powell S, Rut D. Transcranial Doppler mcasurement of middle cerebral artery blood flow velocity: a validation study. Stroke 1986; 17: 913-21.

11 Griesen $G$, Johansen $K$, Ellison P. Cerebral blood flow in the newborn infant: comparison of Doppler ultrasound and xenon 133 clearance. J Pediatrics 1984; 104: 4II-8.

12 Risberg J, Smith P. Prediction of hemispheric blood flow from carotid velocity measurements. A study with the Doppler and 133Xc inhalation techniques. Stroke 1980; 11: 399-403.
13 Baker ML, Dalrymple GV. Biological effects of diagnostic ultrasound: a review. Radiology 1978; 126: 479-83.

14 Florey $H W$. Microscopical obscrvation on the circulation of the blood in the cercbral cortex. Brain 1925; 48: 43-64.

15 Ackerman RH, Zilkha E, Bull JWD et al. The relationship of the $\mathrm{CO}_{2}$ reactivity of cercbral vessels to blood pressure and mean resting blood flow. Neurology 1973; 23: 21-6.

16 Tominaga S Strandgaard S, Uemura $K$ et al. Cercbrovascular $\mathrm{CO}_{2}$ reactivity in normotensive and hypertensive man. Stroke 1976; 7: 507-10.

17 Bissonnette $B$, Lerman J. Single breath end-tidal $\mathrm{CO}_{2}$ estimates of arterial $\mathrm{PCO}_{2}$ in infants and children. Can J Anacsth $1989 ; 36: 2-4$. 